\title{
Modeling water and heat transfer in soil-plant-atmosphere continuum applied to maize growth under plastic film mulching
}

\author{
Meng DUAN ${ }^{1}$, Jin $\mathrm{XIE}^{2}$, Xiaomin MAO (ه্) ${ }^{1}$ \\ 1 Centre for Agricultural Water Research in China/College of Water Resources and Civil Engineering, China Agricultural University, \\ Beijing 100083, China \\ 2 Hunan Polytechnic of Water Resources and Electric Power, Changsha 410131, China
}

\begin{abstract}
Based on our previous work modeling crop growth (CropSPAC) and water and heat transfer in the soilplant-atmosphere continuum (SPAC), the model was improved by considering the effect of plastic film mulching applied to field-grown maize in North-west China. In CropSPAC, a single layer canopy model and a multi-layer soil model were adopted to simulate the energy partition between the canopy and water and heat transfer in the soil, respectively. The maize growth module included photosynthesis, growth stage calculation, biomass accumulation, and participation. The CropSPAC model coupled the maize growth module and SPAC water and heat transfer module through leaf area index (LAI), plant height and soil moisture condition in the root zone. The LAI and plant height were calculated from the maize

$=0.78, \mathrm{RMSE}=49.44 \mathrm{~mm}$ and $\mathrm{E}_{\mathrm{ns}}=0.26$ ). Scenarios were considered to simulate the influence of future climate change and film mulching on crop growth, soil water and heat conditions, and crop yield. The simulations indicated that the change of LAI, leaf biomass and yield are negatively correlated with temperature change, but the growing degree-days, evaporation, soil water content and soil temperature are positively correlated with temperature change. With an increase in the ratio of film mulching area, the evaporation will decrease, while the impact of film mulching on crop transpiration is not significant. In general, film mulching is effective in saving water, preserving soil moisture, increasing soil surface temperature, shortening the potential growth period, and increasing the potential yield of maize.
\end{abstract} growth module and used as input for the SPAC water and heat transfer module, and the SPAC module output for soil water stress conditions used as an input for maize growth module. We used $r_{s}$, the representation of evaporation resistance, instead of the commonly used evaporation resistance $r_{s 0}$ to reflect the change of latent heat flux of soil evaporation under film mulching as well as the induced change in energy partition. The model was tested in a maize field at Yingke irrigation area in North-west China. Results showed reasonable agreement between the simulations and measurements of LAI, above-ground biomass and soil water content. Compared with the original model, the modified model was more reliable for maize growth simulation under film mulching and showed better accuracy for the LAI (with the coefficient of determination $R^{2}=0.92$, the root mean square of error $\mathrm{RMSE}=1.23$, and the Nush-Suttclife efficiency $\mathrm{E}_{\mathrm{ns}}=0.87$ ), the above-ground biomass (with $R^{2}=0.96$, RMSE $=7.17 \mathrm{t} \cdot \mathrm{ha}^{-1}$ and $\mathrm{E}_{\mathrm{ns}}=$ 0.95 ) and the soil water content in 0-1 m soil layer (with $R^{2}$

Received February 15, 2019; accepted March 21, 2019

Correspondence: maoxiaomin@cau.edu.cn
Keywords film mulching, growth stage, leaf area index, maize growth, water and heat transfer

\section{Introduction}

Philip ${ }^{[1]}$ proposed the concept of the soil-plant-atmosphere continuum (SPAC), in which the movement of water is a continuous process. The driving force of water movement can be described by a unified concept of water potential, which better solves the problem of coupling between the changes of underlying surface temperature, humidity and evapotranspiration (ET). In recent decades, various modules have been developed in the SPAC, including the first root water absorption function, which was used to describe the process of root water uptake $\mathrm{e}^{[2,3]}$ and the effective root density and soil solute transport model which simulated soil and root interaction procedures in a physical method avoiding empirical descriptions of root water uptake $^{[4,5]}$. Many improved models have been developed on this basis ${ }^{[6-9]}$. For water transfer in the SPAC, the 
resistance included is the resistance between soil and root, and the resistance between plant and atmosphere. Thom ${ }^{[10]}$ advanced the wind speed profile function by field experiment. Later, Bailey and Davies ${ }^{[11]}$ calculated the boundary layer resistance of the momentum transmission and de Vries ${ }^{[12]}$ and Jarvis ${ }^{[13]}$ gave the expression function of the stomatal resistance.

For the water and heat transfer at the land atmosphere interface, generally there are three methods including a big leaf model ${ }^{[14]}$, single layer model ${ }^{[15]}$ and multi-layer model $^{[16]}$ to simulate the canopy moisture transfer and energy distribution. Of these, the big leaf model was the simplest one as it ignored the moisture and temperature differences between canopy and soil surface. Since it grouped ET together, it was unable to distinguish the evaporation and transpiration, and failed to be used for improving water use efficiency (WUE) in agriculture. The multi-layer model divided the canopy into several layers, which depicted in detail the vertical temperature and humidity differences inside the canopy. However, there were many parameters required and the calculations were complicated, which restricted its usage mainly for forests. Generally, for short and evenly distributed crop canopies, a single layer model which can differentiate the soil evaporation and crop transpiration would be more suitable for the analysis of highly efficient irrigation water use.

A crop model is a computer program designed to simulate the dynamic processes of crop growth, development and yield ${ }^{[17,18]}$. Many models have been used for the maize production systems, such as CERES-Maize ${ }^{[19,20]}$, APSIM-Maize ${ }^{[21]}$, Hybrid-Maize ${ }^{[22]}$, WOFOST $^{[23]}$ and AquaCrop models ${ }^{[24]}$. Those crop models were widely used to simulate crop growth. However, they tend to simplify the water and heat transfer in the SPAC, which may cause errors for deficit irrigation or field mulching. Therefore, in arid and semi-arid areas of North-west China, the models need to be further tested as plastic film mulching is widely used in order to save valuable water resources $^{[25,26]}$.

A new model (CropSPAC) which couples the simulation of winter wheat growth and water and-heat transfer in the SPAC was recently proposed ${ }^{[27]}$. In this model, the SPAC was divided into three levels, including the soil layer, the crop canopy and the atmosphere at a certain reference height. The crop canopy was treated as a single layer, i.e., assuming that the air temperature, humidity and leaf temperature in the crop canopy are homogeneous. Compared with previous crop models, the CropSPAC model considers both the crop growth and the water and heat transfer in the SPAC, especially under deficit irrigation. Crop growth and soil water transfer interactive processes in the CropSPAC model, which describes the change of canopy temperature and humidity, the process of crop leaf area index (LAI) and height change, soil water and heat transfer and root growth status.
Based on this CropSPAC model, here we extended its application to maize and consider the influence of film mulching on the decrease in soil evaporation and the induced change of surface energy partitioning. In addition, the improved model can simulate maize growth, including the photosynthesis, biomass accumulation, LAI, leaf temperature, yield and the growth stages of maize. The improved model was calibrated and validated on a field site with a maize crop in the middle reaches of the Heihe River Basin of China, and was applied to investigate the influence of climate change and local farming management on crop yield and WUE.

\section{Model description}

\subsection{Main modification to the CropSPAC model}

The existing CropSPAC model was developed and tested for winter wheat. Here we focus on maize, another main cereal, which has different growth period. We used growing degree-days to describe the biological processes and considered the quantitative development of thermal effects, photoperiod effects, genetic effects and their relationships to physiological development time scale. However, for cold season crops such as winter wheat, it is necessary to consider the vernalization and thermal sensitivity on the development of wheat growth. Therefore, the module was modified in order to extend the model for maize growth and this is described in Section 2.2.

The heat exchange between the soil system and the external environment included solar radiation, reflected radiation from the ground, sensible heat exchange and latent heat exchange by water-vapor transfer and other processes. Mulching has an effect on heat absorption and heat release by the soil system. The water and heat transfer in the atmosphere-canopy-mulching-soil in the SPAC system of the maize crop in the experimental field was as shown in Fig. 1. Film mulching modified the albedo and the net radiation received by the canopy. Also, it inhibited the turbulent diffusion of vapor from soil surface and greatly increased the evaporation resistance and decreased the soil evaporation, which further modified the energy partitioning and the soil water and heat condition in the soil. Details are given in Section 2.4.

\subsection{Description of the maize growth module}

\subsubsection{Growing degree-days}

Heat units, expressed in growing degree-days (GDD, ${ }^{\circ} \mathrm{C} \cdot \mathrm{d}^{-1}$ ), are frequently used to describe the timing of biological processes ${ }^{[28]}$. The GDD is commonly calculated by, 


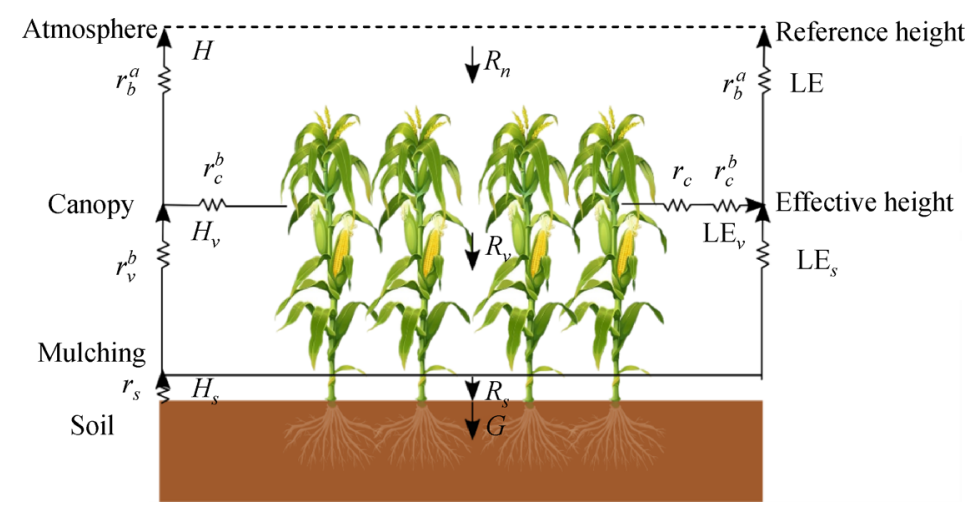

Fig. 1 Diagram of water and heat transfer in CropSPAC (maize growth) under film mulching

$$
\mathrm{GDD}=\left\{\begin{array}{lc}
0, & \left(T_{\max }<T_{b}\right) \\
T_{o}-T_{b}, & \left(T_{o}<T_{\min }\right) \\
\left(T_{\max }+T_{\min }\right) / 2-T_{b}, & \left(T_{b} \leqslant T_{\max }, T_{\min } \leqslant T_{o}\right)
\end{array}\right.
$$

where $T_{o}$ is the optimum temperature, $T_{b}$ is the base temperature, and $T_{\max }$ and $T_{\min }$ are daily maximum and minimum air temperature, respectively.

However, if $T_{\max }$ and $T_{\min }$ do not meet the above conditions, the effect of diurnal temperature difference on crop development need to be considered. This means we need to consider the effects of the diurnal temperature variation on the crop. The following equations ${ }^{[28,29]}$ can be used,

$$
\begin{gathered}
T f a c(i)=\sin (3.14 / 12 \times i) / 2 \\
T(i)= \begin{cases}T_{b}, & \left(T(i) \leqslant T_{b}, \quad T(i)>T_{m}\right) \\
T_{o}, & \left(T_{o} \leqslant T(i) \leqslant T_{m}\right) \\
T(i), & \left(T_{b} \leqslant T(i) \leqslant T_{o}\right)\end{cases} \\
\text { GDD }=\sum\left(T(i)-T_{b}\right) / 24 \\
\text { SUMGDD }=\sum \mathrm{GDD}
\end{gathered}
$$

where $\operatorname{Tfac}(i)(i=1,2, \ldots, 24)$ is the temperature change factors at each time period, $T(i)$ is its corresponding temperature, $T_{m}$ is the highest temperature in the phase of crop growth and SUMGDD is the sum of GDD at each stage.

\subsubsection{Growth stages of maize}

We divided maize growth stages into seven stages according to their genetic characteristics and environmental factors. We considered the quantitative development of thermal effects, photoperiod effects and genetic effects, and established a unified physiological development time scale. The stages of maize are as follows ${ }^{[29]}$.

Stage 1 (the stage from sowing to seedling emergence) The GDD of this stage mainly depends on the thermal effect of the soil. GDD1 is calculated by the cumulative growing degree-days, which can be expressed as,

$$
\text { GDD } 1=45+\text { DTTE } \times \text { SDEPTH }
$$

where DTTE is the cumulative growing degree-days for emergence at each soil depth required, and SDEPTH is the sowing depth of maize. In the process of model simulation, when SUMGDD $\geqslant$ GDD1, it will enter the next growth stage.

Stage 2 (seedling stage)

This stage is from seedling emergence to the end of the seedling stage. The GDD is calculated by P1 (Table 1).

Stage 3 (from the end of seedling stage to the beginning of the elongating stage)

Stage 3 is mainly influenced by the length of the day. It is determined by the total photoperiod induction rate.

$$
\text { RATEIN }=\left\{\begin{array}{lr}
1 /(\text { DJTI }+P 2 \times(\text { DLEN }-P 20)), & \text { DLEN }>P 20 \\
1 / \text { DJTI }, & \text { DLEN } \leqslant P 20
\end{array}\right.
$$

$$
\mathrm{SIND}=\sum \mathrm{RATEIN}
$$

where DLEN is the actual duration of sunshine in hours, $P 20$ is critical day length of maize, and $P 2$ is the increase in the number of days required for duration of sunshine exceeding the critical value for $1 \mathrm{~h}$. DJTI is the minimum growth days required for this growth stage to be independent of photoperiod. SIND is the rate of 
cumulative photoperiod induction for this stage, when its value reaches one, this growth stage ends.

Stage 4 (elongating stage)

This stage is from elongating to silking, described as

$$
\begin{array}{r}
\text { TLNO }=\text { CUMDTT } /(\text { PHINT } \times 0.5)+5 \\
P 3=((\text { TLNO }+0.5) \times \text { PHINT })-\text { CUMDTT }
\end{array}
$$

where TLNO is the total number of leaves, CUMDTT is the cumulative growing degree-days of Stages 2 and 3, PHINT is the leaf interval, and $P 3$ is the GDD of Stage 4.

Stage 5 (tasseling stage)

This stage is from silking stage to the effective grouting period. The cumulative growing degree-days is calculated by DSGFT (Table 1$)$.

Stage 6 (grouting stage)

The controlling factor for the effective grouting period is the temperature, described as

$$
\mathrm{SUMDTT} \geqslant P 5 \times 0.95
$$

where SUMDTT is the cumulative photoperiod induction for this stage. When the above formula is met, this phase ends. $P 5$ is the GDD of Stage 6.

Stage 7 (maturing stage)

This stage is from the end of the effective grouting stage to the pre-harvest period.

When the cumulative GDD of Stages 5-7 reaches P5, the simulation of the whole maize development stage is complete. Stage 7 is the stage of maturity. Parameters used in the growth stages of maize are summarized in Table $1^{[29]}$.

\subsubsection{Canopy photosynthesis}

\subsubsection{Leaf photosynthesis}

In CropSPAC, the daily potential leaf photosynthesis is calculated with the exponential model described by Thornley ${ }^{[30]}$, and further modified by Collatz et al. ${ }^{[31]}$,

$$
\begin{gathered}
\mathrm{FG}=P_{\max } \times\left(\varepsilon \times I_{L}\right) /\left(\varepsilon \times I_{L}+P_{\max }\right) \\
P_{\text {max }}=P_{\text {max }}^{0} \times f_{\mathrm{CO}_{2}} \times f_{T}
\end{gathered}
$$

where $F G$ is the photosynthetic rate of leaves in $\mathrm{kg} \cdot \mathrm{ha}^{-1} \cdot \mathrm{h}^{-1}$ $\mathrm{CO}_{2}, P_{\max }$ is the maximum rate of leaf photosynthesis, with value $40 \mathrm{~kg} \cdot \mathrm{ha}^{-1} \cdot \mathrm{h}^{-1} \mathrm{CO}_{2}, \varepsilon$ is the initial slope of photosynthetic light response in $\left(\mathrm{kg} \cdot \mathrm{ha}^{-1} \cdot \mathrm{h}^{-1}\right) /\left(\mathrm{J} \cdot \mathrm{m}^{-2} \cdot \mathrm{s}^{-1}\right)$ $\mathrm{CO}_{2}, I_{L}$ is the photosynthetic active radiation intensity at depth $L$ of crop canopy in $\mathrm{J} \cdot \mathrm{m}^{-2} \cdot \mathrm{s}^{-1}$, and $P_{\max }^{0}$ is the photosynthetic rate of a single leaf, taking into account factors of temperature and $\mathrm{CO}_{2}$ concentration, in $\mathrm{J} \cdot \mathrm{m}^{-2} \cdot \mathrm{s}^{-1}$.

\subsubsection{Scaling up from leaf to canopy}

The calculation formula of canopy stratification is,

$$
\operatorname{LGUSS}[i]=\operatorname{DIS}[i] \times \operatorname{LAI}(i=1,2,3,4,5)
$$

where LGUSS $[i]$ is the canopy depth in Gauss stratified, LAI is the leaf area index, and DIS $[i]$ is the distance coefficient of Gauss's five-point integral method.

Photosynthetically active radiation absorbed by each layer of canopy $I_{L}[i, j]\left(\mathrm{J} \cdot \mathrm{m}^{-2} \cdot \mathrm{s}^{-1}\right)$ is,

$$
I_{L}[i, j]=(1-\rho[j]) \times \operatorname{PARCAN} \times \kappa \times e^{-\kappa \times \operatorname{LGUSS}[i]}
$$

Photosynthesis rate at each layer of the canopy $\mathrm{FG}[i, j]$ $\left(\mathrm{kg} \cdot \mathrm{ha}^{-1} \cdot \mathrm{h}^{-1} \quad \mathrm{CO}_{2}\right)$ is,

$$
\mathrm{FG}[i, j]=\mathrm{PLMX} \times\left[1-e^{\left(-\varepsilon \times I_{L}[i, j] / \mathrm{PLMX}\right.}\right]
$$

\begin{tabular}{|c|c|c|c|c|}
\hline Parameter & Description & Value range & Value & Unit \\
\hline$\overline{T_{b}}$ & Base temperature of maize growth & - & 8 & ${ }^{\circ} \mathrm{C}$ \\
\hline$T_{o}$ & Optimum temperature of maize growth & - & 34 & ${ }^{\circ} \mathrm{C}$ \\
\hline$T_{m}$ & Maximum temperature of maize growth & - & 44 & ${ }^{\circ} \mathrm{C}$ \\
\hline GDD & Growing degree-days & - & 6 & ${ }^{\circ} \mathrm{C} \cdot \mathrm{d}^{-1} \cdot \mathrm{cm}^{-1}$ \\
\hline$P 1$ & GDD of Stage 2 & $5-450$ & 352 & ${ }^{\circ} \mathrm{C} \cdot \mathrm{d}^{-1}$ \\
\hline$P 20$ & Critical day length of maize & - & 12.5 & $\mathrm{~h}$ \\
\hline$P 2$ & Days with increased hours of sunshine & $0-2$ & 0.796 & $d \cdot h^{-1}$ \\
\hline DJTI & GDD of Stage 3 & - & 4 & d \\
\hline PHINT & Leaf interval & - & 75 & ${ }^{\circ} \mathrm{C} \cdot \mathrm{d}^{-1}$ \\
\hline DSGFT & GDD of Stage 5 & - & 170 & ${ }^{\circ} \mathrm{C} \cdot \mathrm{d}^{-1}$ \\
\hline$P 5$ & GDD of Stage 6 & $580-999$ & 600 & ${ }^{\circ} \mathrm{C} \cdot \mathrm{d}^{-1}$ \\
\hline$\alpha$ & The ratio of film mulching area & $0-1$ & 0.7 & - \\
\hline
\end{tabular}

Instantaneous photosynthetic rate of canopy $\mathrm{FG}[j]$ $\left(\mathrm{kg} \cdot \mathrm{ha}^{-1} \cdot \mathrm{h}^{-1} \mathrm{CO}_{2}\right)$ is,

$$
\mathrm{FG}[j]=\left(\sum_{i=1}^{5} \mathrm{FG}[i, j] \times \mathrm{WT}[i]\right) \times \mathrm{LAI}
$$

Table 1 Parameters used in the maize growth stages 
The daily canopy photosynthesis amount DTGA $\left(\mathrm{kg} \cdot \mathrm{ha}^{-1} \cdot \mathrm{h}^{-1} \mathrm{CO}_{2}\right)$,

$$
\mathrm{DTGA}=\left(\sum_{j=1}^{3} \mathrm{FG}[j] \times \mathrm{WT}[j]\right) \times \mathrm{DL}
$$

Equations (18)-(22) are applied to calculate canopy photosynthesis by Gauss integration.

$$
A_{c}=\mathrm{DTGA} \times \min \left(f_{W}, f_{N}\right)
$$

where the value $A_{c}$ is the actual daily total assimilation, $f_{W}$ is the water influence factor, and $f_{N}$ is the nitrogen influence factor.

The temperature response function is expressed as,

$$
f_{T}=1-T_{C} \times\left(T_{\text {day }}-T_{o}\right)^{2}
$$

where $T_{c}$ is a parameter on temperature, $T_{\text {day }}$ is the daily average temperature, and $T_{o}$ is the optimal temperature $\left({ }^{\circ} \mathrm{C}\right)$ for photosynthesis.

$\mathrm{CO}_{2}$ concentration response function is expressed as,

$$
f_{\mathrm{CO}_{2}}=1+\beta \ln \left(C_{x} / C_{0}\right)
$$

where $f_{\mathrm{CO}_{2}}$ is the effect factor of ambient $\mathrm{CO}_{2}$ concentration on photosynthetic rate, $C_{x}$ is the $\mathrm{CO}_{2}$ concentration, ppm, $C_{0}$ is the reference $\mathrm{CO}_{2}$ concentration (usually $380 \mathrm{ppm}$ ), and $\beta$ is the empirical coefficient.

The water content response function is expressed as,

$$
f_{w}=\left(\frac{T_{a i}}{T_{p i}}\right)^{\sigma}
$$

where $T_{a i}$ is the actual transpiration for day $i, T_{p i}$ is the potential transpiration for day $i$, and $\sigma$ is the water deficit sensitivity parameter.

The $\mathrm{N}$ response function is expressed as,

$$
f_{N}=\frac{N_{c}-N_{\min }}{N_{\mathrm{opt}}-N_{\min }}
$$

where $N_{c}$ is the leaf $\mathrm{N}$ concentration, $N_{\text {opt }}$ is the leaf $\mathrm{N}$ concentration at which the effect on photosynthesis is unity, and $N_{\min }$ is the leaf $\mathrm{N}$ concentration at which the photosynthesis ceases. The response function to phosphorus has the same equation but with the parameters for $\mathrm{P}$ and leaf $\mathrm{P}$ concentration.

\subsubsection{Crop respiration}

Crop respiration is divided into two parts, i.e., growth respiration and maintenance respiration ${ }^{[32]}$. Maintenance respiration is estimated with $Q_{10}$ (temperature coefficient) expression,

$$
\mathrm{RM}=R_{m}\left(T_{o}\right) \times A_{c} \times Q_{10}^{\left(T_{\text {mean }}-T_{\text {day }}\right) / 10}
$$

where $\mathrm{RM}$ is the maintenance respiration, $R_{m}\left(T_{o}\right)$ is the coefficient of sustained respiration at $\mathrm{T}_{o}, Q_{10}$ is the temperature coefficient, and $T_{o}$ is the optimal temperature $\left({ }^{\circ} \mathrm{C}\right)$ for respiration.

Crop growth respiration is estimated with the equation proposed by Iersel and Seymour ${ }^{[33]}$,

$$
\mathrm{RG}=R_{g} \times(\mathrm{FDGA}-\mathrm{RM})
$$

where RG is growth respiration, and $R_{g}$ is the growth respiration coefficient.

\subsubsection{Dry biomass accumulation}

CropSPAC model of canopy net assimilation rate is calculated as,

$$
\mathrm{PND}=A_{c}-\mathrm{RM}-\mathrm{RG}
$$

Daily dry biomass of maize is calculated as,

$$
\begin{gathered}
\text { TDRW }=\zeta \times 0.95 \times \mathrm{PND} /(1-0.05) \\
\zeta=\frac{\left(\mathrm{CH}_{2} \mathrm{O}\right)}{\left(\mathrm{CO}_{2}\right)}=\frac{30}{44}=0.682 \\
W_{\text {day }, t}=W_{\text {day }, t-1}+\mathrm{TDRW}
\end{gathered}
$$

where TDRW is the dry biomass of maize, $\zeta$ is the conversion coefficients between $\mathrm{CO}_{2}$ and organic compounds, and $W_{\text {day }}$ is the accumulation of dry matter.

\subsubsection{Biomass partition}

Generally, living plants are virtually divided into four components, i.e., leaf, stem, seed and root. Dead materials from the living components contribute to the above ground litter pool and root litter pool. Living leaves absorb atmospheric $\mathrm{CO}_{2}$ by the photosynthetic process. Carbon then flows from leaves to stems and roots. Nutrients absorbed by roots are allocated to living leaves and stems. During the reproductive phase, $\mathrm{C}, \mathrm{N}$ and $\mathrm{P}$ from leaves and stems retranslocated to seeds. Here the assimilate distribution of each component is given by

$$
f_{i}(t)=\frac{W_{i}(t+1)-W_{i}(t)}{\operatorname{TDRW}}
$$

where $f_{i}(t)$ is the allocation coefficient of each component, with $i=1,2$ and 3 representing stem, leaf and grain respectively, and $W_{i}(t)$ is the dry matter of $i$ component on day $t$.

The maize distribution coefficient calculation is expressed as,

$$
\mathrm{DVS}=\frac{\sum_{i=1}^{n} \mathrm{DTT}_{i}}{\text { TSDTT }}
$$




$$
f_{\mathrm{ds}}= \begin{cases}0.47, & \mathrm{DVS}<0.3 \\ 0.372+0.56 \mathrm{DVS}, & 0.3 \leqslant \mathrm{DVS}<0.8 \\ 1, & \mathrm{DVS} \geqslant 0.8\end{cases}
$$

where DVS is crop development index after emergence to maturity, $\mathrm{DTT}_{i}$ is the effective accumulated temperature of $i$ days after emergence, TSDTT is the cumulative effective temperature required from emergence to silking stage, CSDTT is the cumulative effective temperature required from silking stage to maturity period, and $f_{\mathrm{ds}}$ is the distribution coefficient of dry matter to the underground parts of maize.

The distribution coefficient of each component is described as follows,

$$
\begin{gathered}
f_{1}= \begin{cases}0.7, & \text { DVS }<0.8 \\
\frac{8}{7} \mathrm{DVS}-\frac{1}{7}, & 0.8 \leqslant \mathrm{DVS}<1 \\
1-\frac{\mathrm{DVS}-1}{1.26-1}, & 1 \leqslant \mathrm{DVS}<1.26 \\
0, & \mathrm{DVS} \geqslant 1.26\end{cases} \\
f_{2}= \begin{cases}0.3, & \mathrm{DVS}<0.8 \\
-\frac{8}{7}+\frac{8}{7} \mathrm{DVS}, & 0.8 \leqslant \mathrm{DVS}<1 \\
0, & \mathrm{DVS} \geqslant 1\end{cases} \\
f_{3}= \begin{cases}0, & \mathrm{DVS}<1 \\
\frac{\mathrm{DVS}-1}{1.26-1}, & 1 \leqslant \mathrm{DVS}<1.26 \\
1, & \mathrm{DVS} \geqslant 1.26\end{cases} \\
\Delta W_{i}(t)=\mathrm{TDRW} \times f_{i}(t)
\end{gathered}
$$

And each component is expressed as,

$$
\begin{gathered}
W_{\text {leaf }, t}=W_{\text {leaf }, t-1}+\Delta W_{i}(t), i=1 \\
W_{\text {stem }, t}=W_{\text {stem }, t-1}+\Delta W_{i}(t), i=2 \\
W_{\mathrm{zl}, t}=W_{\mathrm{zl}, t-1}+\Delta W_{i}(t), i=3
\end{gathered}
$$

where $W_{\text {leaf }}$ is the leaf dry matter accumulation, $W_{\text {stem }}$ is the stem dry matter accumulation, and $W_{\mathrm{zl}}$ is the grain dry matter accumulation.

\subsubsection{Crop biomass yield formation}

Crop models are useful tools for estimating crop growth and yield. For the purpose of yield prediction, predecessors have constructed the function of yield and its influencing factors, including constructing the relationship between dynamics of dry matter accumulation and grain yield (e.g.,
CERES model) and the relationship function between crop yield and water production response (e.g., AquaCrop) to simulate yield.

The photosynthetic products of maize are mainly distributed to root, leaf, stem and seed, and the percentage of each distributed part depends on the development phase of maize. Previous studies estimated that the dry matter accumulation of stem and leaf accounts for about one-third of the total photosynthetic yield at the early stage of silking while the other two-thirds came from the accumulation of dry matter from photosynthesis after silking ${ }^{[34]}$.

$$
\begin{gathered}
\mathrm{YIELD}=(\mathrm{YBS} \times \mathrm{KBS}+\mathrm{YAS} \times \mathrm{KAS}) \times(1+\delta) \\
\mathrm{KBS}=1 / 3 \times \mathrm{HI} \times(1+\alpha) \\
\mathrm{KAS}=2 / 3 \times \mathrm{HI} \times\left(1+\frac{1}{\alpha}\right) \\
\alpha=\frac{\mathrm{YAS}}{\mathrm{YBS}}
\end{gathered}
$$

where YBS is the net dry matter by photosynthetic before the silking stage, KBS is the transfer rate of dry matter from stem and leaf to grain before the silking stage, YAS is the net dry matter by photosynthetic after the silking stage, KAS is the transfer rate of dry matter accumulation in grain after the silking stage, $\delta$ is the water content of grain, $\alpha$ is the ratio of dry matter weight by net photosynthesis before and after silking, and $\mathrm{HI}$ is the harvest index.

\subsubsection{Leaf area index}

LAI is was calculated by the allocation coefficient method as,

$$
\begin{gathered}
\Delta \mathrm{LAI}=\frac{\Delta W_{2}}{Z} \\
Z=19.821+0.0786 T-0.00002 T^{2} \\
\mathrm{LAI}_{i}=\mathrm{LAI}_{i-1}(1-\mathrm{DR})+\Delta \mathrm{LAI} \\
\mathrm{DR}=0.0002 e^{5.5 \mathrm{PF}} \\
\mathrm{PF}=\frac{\mathrm{SDD}}{\mathrm{CSDTT}}
\end{gathered}
$$

where $\Delta \mathrm{LAI}$ is the variation of LAI, $\Delta W_{2}$ is the transformation of leaf weight, $Z$ is the density of specific leaf area, DR is the leaf mortality rate, and SDD is the cumulative effective temperature required after silking stage. 


\subsubsection{Plant height}

Plant height was affected by the daily dry biomass accumulation of maize ${ }^{[35]}$. Maize height was described by an empirical formula as,

$$
h=47.273 \times \ln \left(W_{\mathrm{ds}, t}\right)-260.42
$$

where $h$ is maize height, and $W_{\mathrm{ds}, t}$ is the accumulation of dry matter on $t$ day.

\subsection{Influence of film mulching on the SPAC water and heat transfer}

Although the evaporation rate with film mulching is much lower than that from bare soils, the evaporation process from the soil surface is not negligible, especially over the long-term. Evaporation from bare soil depends on a combination of micrometeorological factors and soil properties. Film mulching mainly influences the soil surface albedo and vapor exchange between the soil surface and canopy. As a result, both the net radiation and the energy partitioning in the canopy, e.g., latent heat and sensible heat and heat flux are modified by the film mulching ${ }^{[36]}$.

The soil surface evaporation with film mulching, $\mathrm{LE}_{s}$, decreased dramatically compared with soil evaporation without mulching $\mathrm{LE}_{s 0}$, and is here assumed to be a linear relationship with the ratio of film mulching area $(\alpha)$. Therefore, the latent heat of soil evaporation under film mulching can be calculated based on $\mathrm{LE}_{s 0}$, the latent heat of soil evaporation without film mulching,

$$
\mathrm{LE}_{s}=(1-\alpha) \mathrm{LE}_{s 0} \text { with } \mathrm{LE}_{s 0}=\frac{\rho C_{p}\left(e_{1}-e_{b}\right)}{\gamma\left(r_{s b}+r_{s 0}\right)}
$$

For the convenience of model calculation (and consistency with the formula of the previous model simulation), the form of $\mathrm{LE}_{s}$ was modified as,

$$
\mathrm{LE}_{s}=\frac{\rho C_{p}\left(e_{1}-e_{b}\right)}{\gamma\left(r_{s b}+r_{s}\right)}
$$

where $\rho$ is air density, $C_{p}$ is the specific heat capacity at constant pressure, $\gamma$ is the hygrometeric constant, $e_{1}$ is the water vapor pressure on the soil surface, and $e_{b}$ is water vapor pressure of crop canopy.

The soil surface resistance for water vapor transfer is correlated with the length of the soil diffusion pathway ${ }^{[37]}$, although film mulching changes the length of this pathway. It is assumed that the vapor exchange between the soil surface and mulching is uniform over a relatively short distance under film mulching.

Therefore, the equivalent soil evaporation resistance with film mulching $r_{s}$ can be expressed as,

$$
r_{s}=\frac{\alpha r_{s b}}{1-\alpha}+\frac{r_{s 0}}{1-\alpha}
$$

where $r_{s b}$ is the aerodynamic resistance determined by the wind speed profile (details are shown in CropSPAC mode ${ }^{[27]}$, and $r_{s 0}$ is the evaporation resistance of soil surface without film mulching, which is related to soil water content near the soil surface layer (as described in CropSPAC model ${ }^{[27]}$ ).

In this case, the model with film mulching could be simulated with the previous model flowchart as shown in Yang et al. ${ }^{[27]}$, by modification of soil evaporation resistance in the input data.

\subsection{The operation of the improved model}

The improved model consists of two main modules, the first portion involves maize growth modules which includes photosynthesis, growth stage calculation and biomass accumulation. The second module is to simulate soil water and heat transfer and the energy distribution in the SPAC during crop growth based on the process of soil water stress.

The model presented here requires input data containing initial water content and temperature along the soil profile, daily meteorological data, soil hydraulic properties and heat transfer parameters, and crop growth information. As a result, the model output includes LAI, above-ground biomass, soil water content and soil temperature. The objective of developing this model was to predict WUE under the climate change and to provide reasonable agricultural irrigation management measures.

\subsection{Statistics}

The performance of the measured and simulated results using the improved model were compared by evaluating the coefficient of determination $\left(R^{2}\right)$, the root mean square of error (RMSE) of the linear regressions and NushSuttclife efficiency $\left(\mathrm{E}_{\mathrm{ns}}\right)$ between the measured and the simulated values of LAI, and above-ground biomass.

$$
\begin{gathered}
R^{2}=\left[\frac{\sum_{i=1}^{N}\left(S_{i}-\bar{S}\right)\left(O_{i}-\bar{O}\right)}{\sqrt{\sum_{i=1}^{N}\left(S_{i}-\bar{S}\right)^{2} \sum_{i=1}^{N}\left(O_{i}-\bar{O}\right)^{2}}}\right]^{2} \\
\mathrm{RMSE}=\sqrt{\frac{1}{N} \sum_{i=1}^{N}\left(S_{i}-O_{i}\right)^{2}} \\
\mathrm{E}_{\mathrm{ns}}=1-\frac{\sum_{i=1}^{N}\left(O_{i}-S_{i}\right)^{2}}{\sum_{i=1}^{N}\left(O_{i}-\bar{O}\right)^{2}}
\end{gathered}
$$


where $N$ is the number of observations, $S_{i}$ is the simulated value, and $O_{i}$ is the measured value

\section{Study area and model input}

The data to test the CropSPAC model were collected from a field cropped to maize in 2012. The field experiment was located at $100^{\circ} 30^{\prime} \mathrm{E}$ and $38^{\circ} 55^{\prime} \mathrm{N}$ in Yingke irrigation area, which is located in the middle reaches of the Heihe River Basin of China. The mean annual temperature is $6.5-7^{\circ} \mathrm{C}$, and the minimum temperature is $-28^{\circ} \mathrm{C}$, the highest temperature is $33.5^{\circ} \mathrm{C}$. The annual precipitation is about $125 \mathrm{~mm}$ with most occurring in summer.

Daily meteorological data were collected by a weather station at the experimental site, including air temperature, air humidity, solar radiation, sunshine hours, atmospheric pressure and wind speed, as well as the precipitation. Soil water content was measured to a depth of $160 \mathrm{~cm}$ using an oven drying method. Crop canopy characteristics, such as LAI, biomass on the ground and yield, were also measured in the field.

The input for the model included daily meteorological data (i.e., solar radiation, maximum and minimum air temperature, relative humidity, irrigation and precipitation), the physical soil parameters and crop growth, and the initial soil water content and temperature profile data. All these experiments were conducted to simulate crop growth and soil water and heat transfer under related conditions (e.g., soil water content, soil temperature, evaporation and transpiration, LAI, above-ground biomass and yield). Soil water content and soil temperature data at the beginning of simulation were given by interpolation of soil temperature and water content profile data of measured values.

\section{Comparisons of simulations with experimental results}

The simulations were compared with the experimental results both for the soil water/heat dynamics and the crop growth index and yield.

\subsection{Soil water content}

Mulching formed an impermeable barrier on the soil surface, for this reason the vertical transfer of soil water by evaporation was reduced, the horizontal movement of water (to the uncovered area) and evaporation (through holes in the film) were enhanced, the evaporation rate of soil water was reduced and the total evaporation from the soil layer was reduced ${ }^{[38]}$. Given that the distance between the mulch and the soil surface is relatively short, the horizontal movement of water was ignored and only vertical evaporation of water through holes in the film was considered. The comparison of simulated and measured soil water storage in soil depth $0-1 \mathrm{~m}$ during maize growing period is shown in Fig. 2. These were in reasonable agreement, showing a sharp increase of soil water storage after irrigation/precipitation (i.e., irrigation on 26 May, 22 June, 21 July and 13 August and precipitation on 27 June) and a gradual decrease (mainly caused by ET) over time.

The CropSPAC model can appropriately simulate the change of soil water content in the $0-1 \mathrm{~m}$ soil layer compared to the measured value, with $R^{2}$ of 0.78 , RMSE of $49.44 \mathrm{~mm}$ and $E_{\mathrm{ns}}$ of 0.26 . However, the simulated soil water storage seemed to be lower than the measured value at the mature stage. The most likely reason was that we proposed an empirical formula for stomatal conductance

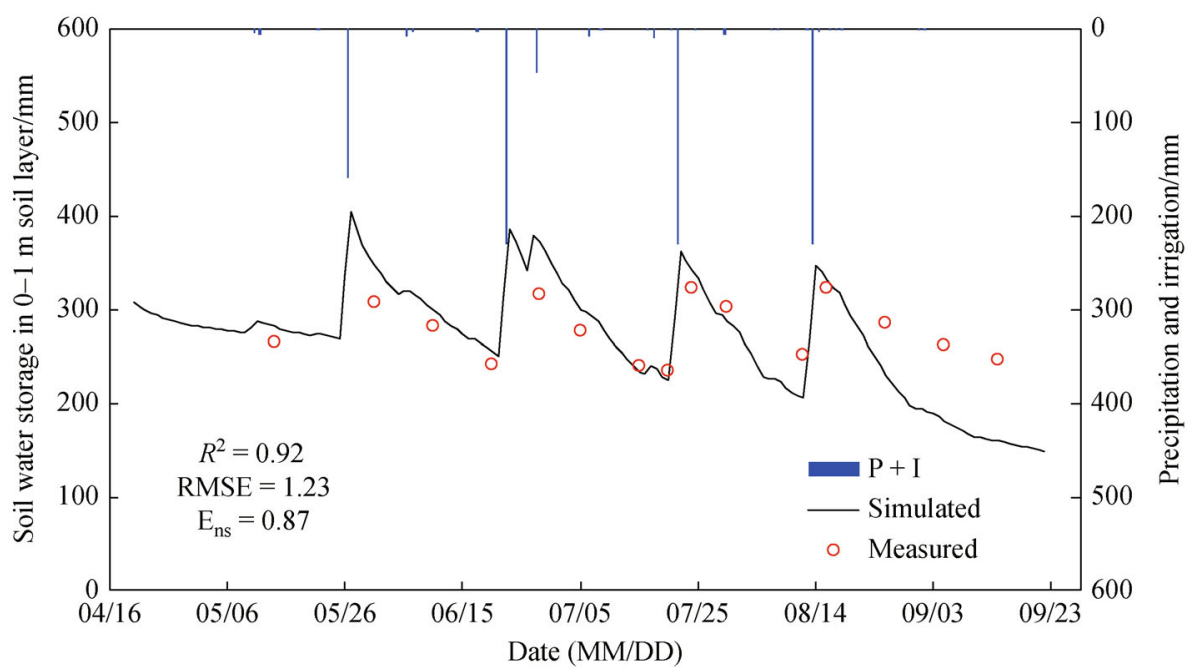

Fig. 2 Comparison between simulated and measured soil water storage in 0-1 $\mathrm{m}$ soil layer 
during the whole growth period of maize that cannot simulate the changes in stomatal conductance at the dufferent growth stages. This may be caused by the decrement of leaf stomatal conductance in the later growth stage of crops and the increment of canopy total stomatal resistance $\left(r_{\mathrm{c}}\right)$, leading to the decrease in the leaf latent heat $\left(\mathrm{LE}_{v}\right)$ and the increase in soil latent heat $\left(\mathrm{LE}_{s}\right)$. As a result, in the simulation before jointing stage, the simulated value of stomatal conductance was higher than the measured value, whereas the simulated value in the mature stage was lower. Finally, the simulated value of soil moisture in the early growth stage was higher than the measured value, while in the later growth stage the simulated value tended to be lower.

Under film mulching, the vertical distribution of soil water content was affected by four factors, namely, rainfall, crop transpiration, infiltration resistance and evaporation resistance ${ }^{[39]}$. Figure 3 shows the comparison of simulated and measured soil water profile at a random date. As soil water evaporates and condenses into droplets under the film and then returns to the soil, the soil surface was replenished with water, result in the measured water content higher than the simulated value, which is more obvious for the end of the elongating stage (15 June).

\subsection{Soil temperature}

Figure 4 shows the simulated processes of daily averaged soil temperature at four soil depths during maize growth (note that there is no measured soil temperature data). The net radiation at the soil surface $\left(R_{S}\right)$ was mainly absorbed by the soil and was converted to latent heat $\left(\mathrm{LE}_{s}\right)$, sensible heat $\left(H_{s}\right)$ and the downward heat flux $(G)$. After mulching, the soil latent heat exchange was weakened and trended to zero and then the soil surface sensible heat flux increased, and the thermal insulation effect of mulching reduced soil
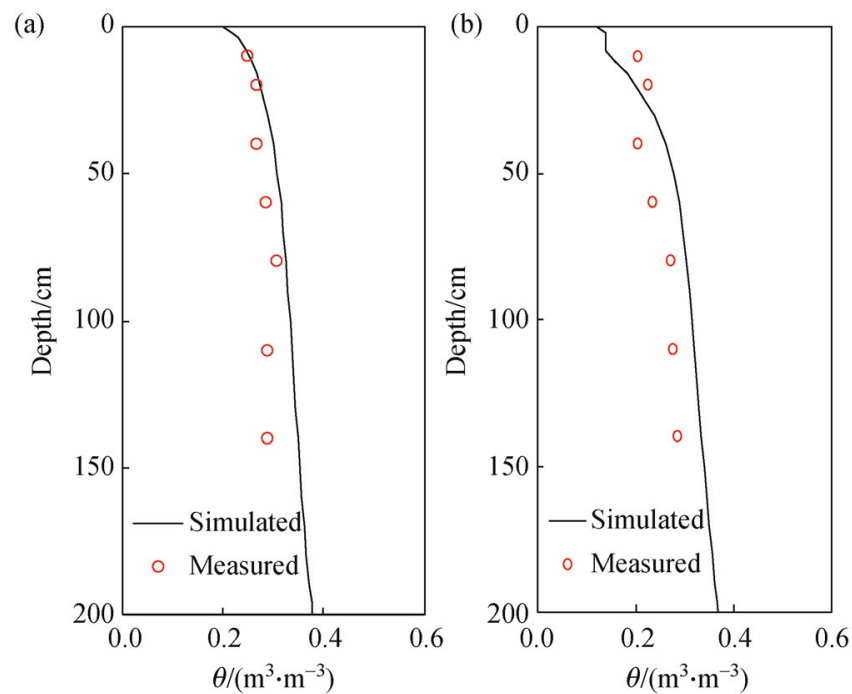

temperature loss significantly. Secondly, mulching reduced the exchange of water-vapor transfer between soil surface and outside, thus the loss caused by latent heat exchange was reduced. Thirdly, because the film and the condensing droplet on its surface had a greater weakening effect on the long-wave radiation exchange, the effective radiation of the soil was reduced at night, and the temperature decline smaller than before, which has an effect of heat preservation.

The soil temperature fluctuated more near the soil surface than at depth. The range of soil temperature at $10 \mathrm{~cm}$ was the largest, ranging from 7.4 to $22.5^{\circ} \mathrm{C}$. Meanwhile, the change at 50,100 and $150 \mathrm{~cm}$ was smaller, and within $10^{\circ} \mathrm{C}$. During the whole period of maize growth, the daily average ground temperature decreased with soil depth. This is because the soil surface is significantly influenced by atmosphere temperature ${ }^{[40-42]}$. From the end of the elongating stage (15 June) to the grain filling stage (10 August), the soil temperature fluctuated less than at the earlier and later stages, and the fluctuations were greater on the soil surface, and were smaller than expected at 50 and $100 \mathrm{~cm}$.

Figure 5 shows the temperature profiles over several typical days. The simulated temperature profiles at 8:00, 16:00 and 24:00 are given. The simulation values below $20 \mathrm{~cm}$ are identical at different times. The intraday topsoil temperature varies greatly, with the surface temperature rising gradually at 8:00, and dropping at about 16:00, reaching its lowest value at about 8:00 the next day.

\subsection{Evaporation and transpiration}

Bare soil evaporation is determined solely by micrometeorological condition (i.e., solar radiation, air temperature and humidity and wind speed) when the amount of water available for evaporation at the soil surface is unlimited ${ }^{[43]}$.
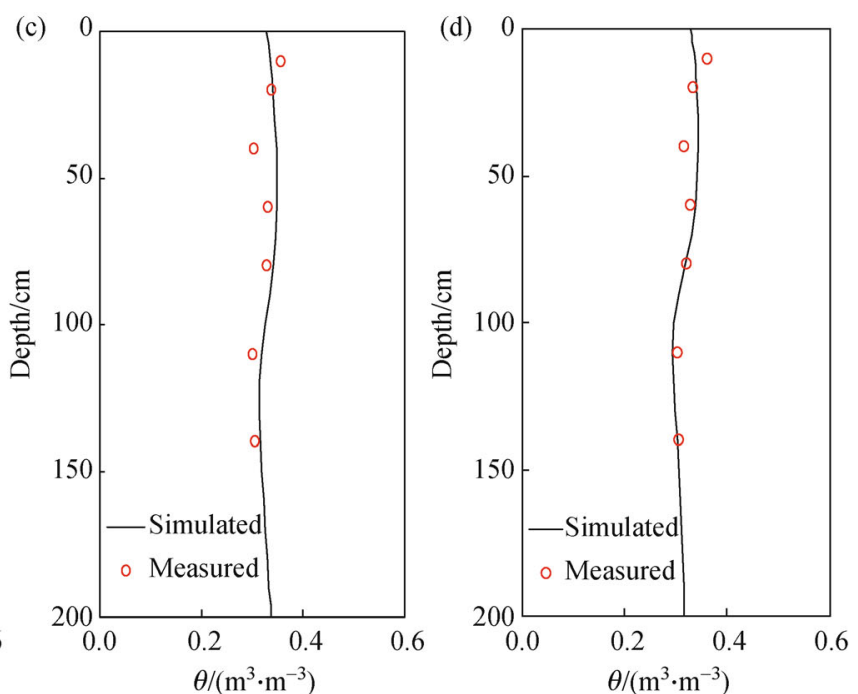

Fig. 3 Comparison between simulated and measured soil water content at 10 June (a), 20 June (b), 24 July (c) and 16 August (d) 

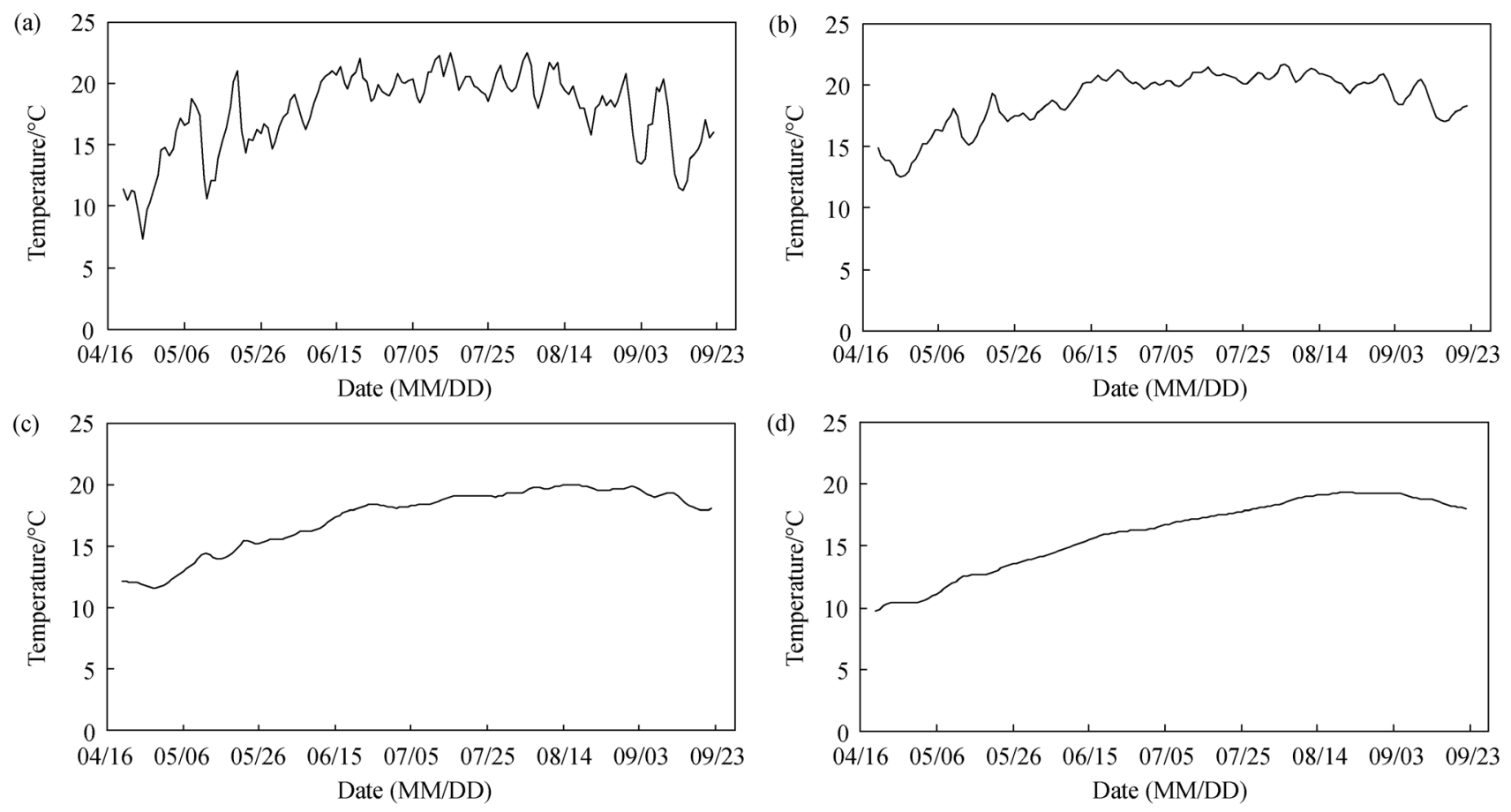

Fig. 4 Daily averaged soil temperature simulated processes at depths of 10 (a), 50 (b), (c) 100 (c) and $150 \mathrm{~cm}$ (d)
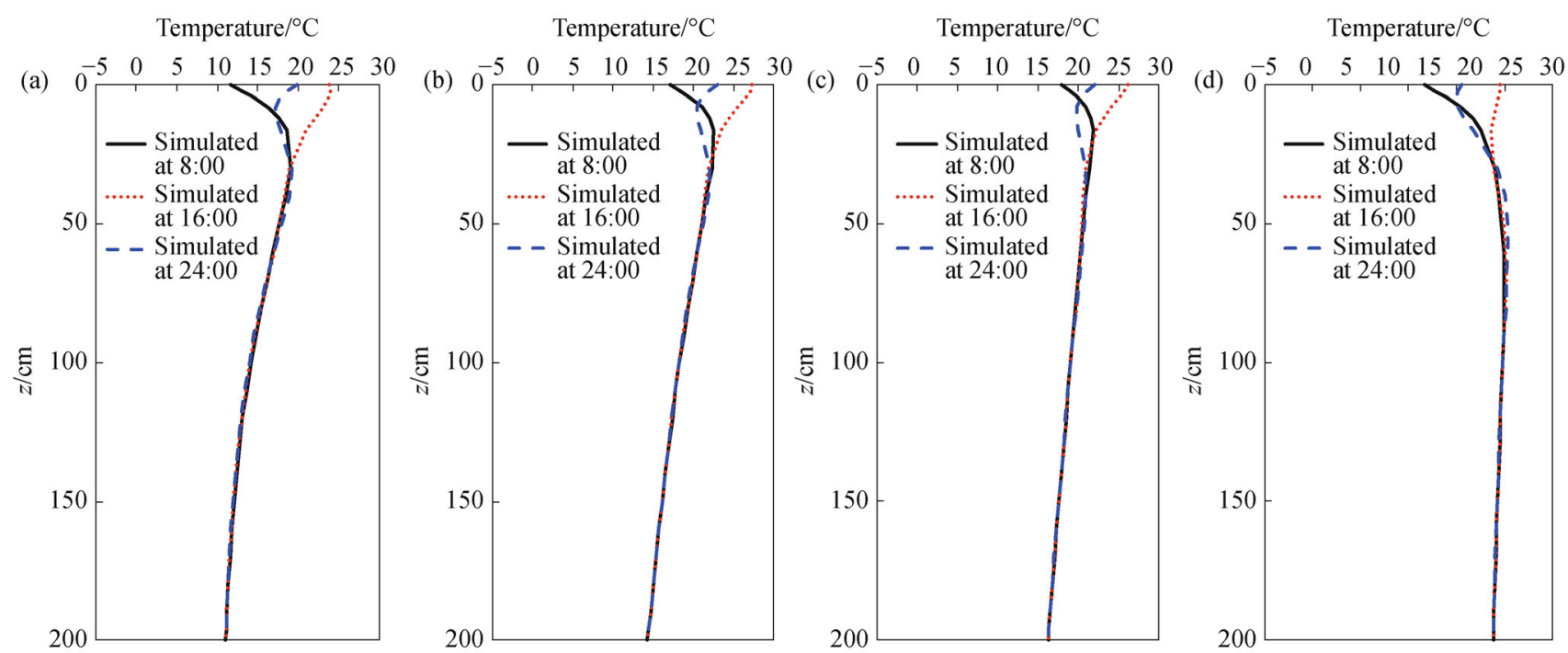

Fig. 5 Simulated values of soil temperature profiles at different times (8:00, 16:00, 24:00) on 10 May (a), 22 June (b), 21 July (c) and 1 September (d)

Mulching effectively prevented non-beneficial evaporation of soil water in the early stage of maize growth and created favorable conditions for water consumption in the late growth stage. The significance of water-saving under film mulching lies in restraining vertical evaporation and turbulent exchange of soil moisture, causing horizontal transport of moisture, increasing the resistance of moisture evaporation and inhibiting non-beneficial evaporation of soil moisture ${ }^{[4]}$. Simultaneously, film mulching promotes the effective circulation of water in the SPAC, increases the water storage of soil tillage layer and improves crop absorption of water ${ }^{[45]}$.

The simulated daily evaporation, transpiration and cumulative ET processes during crop growth period are shown in Fig. 6. Compared with bare soil evaporation, mulching can control soil evaporation in a maize crop. The values of soil evaporation range from 0 to $4.25 \mathrm{~mm}$ during the whole maize growth stage and the range gradually 


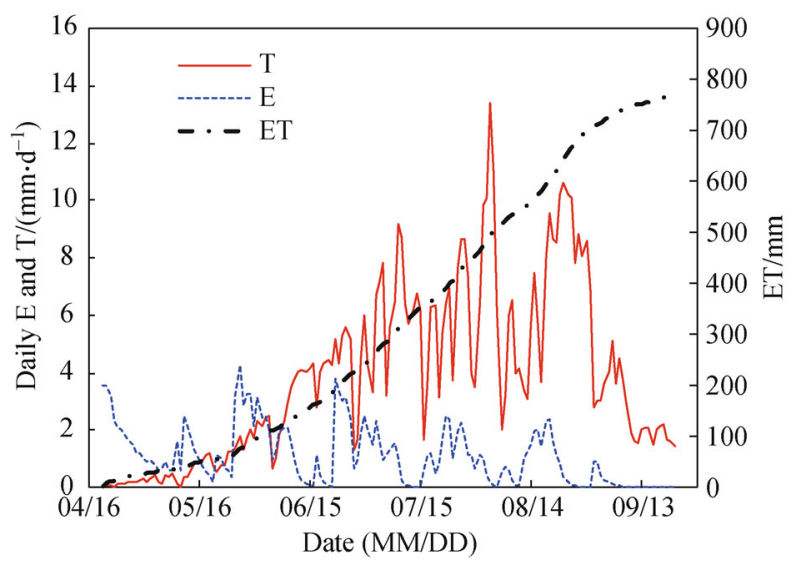

Fig. 6 Daily evaporation (E), transpiration (T) and cumulative evapotranspiration (ET) processes during simulation period for crop growth

decreases after the jointing stage. This is mainly caused by the decrease of net radiation reaching the soil surface along with the increase of canopy coverage. With the increase of LAI and root water absorption capacity, crops can make better use of soil moisture ${ }^{[46]}$. With the development of roots deeper in the soil, crops can make full use of soil moisture in the middle and lower soil layers, resulting in a significant increase in transpiration loss of the crop in the field $^{[47]}$.

With the increase of LAI and air temperature, crop transpiration gradually increased and reached its maximum value in early August. At the mature stage of maize, the transpiration of the crop decreased rapidly, which was due mainly to the decrease of crop LAI and the atmosphere potential evaporation capacity. There was large fluctuation caused mainly by the variation of daily weather condition and daily transpiration. The soil evaporation did not vary concurrently with the transpiration, although both are influenced by the variation in daily weather conditions. This is because soil evaporation was controlled by soil surface moisture conditions. Therefore, after each irrigation, the wet topsoil will increase soil evaporation to some extent, and then with decrease of soil surface moisture, evaporation will gradually decrease. The irrigation/precipitation had no obvious effect on crop transpiration, which was mainly influenced by root water uptake, i.e., the soil water conditions in the root zone.

\subsection{Leaf area index}

Comparisons between measured and simulated LAI in the whole growth period are shown in Fig. 7. Both increased in the early growth stage and then decreased after reaching the maximum value in early August. In general, the simulated results agree well with the measured ones with $R^{2}=0.92, \mathrm{RMSE}=1.23$ and $\mathrm{E}_{\mathrm{ns}}=0.87$. The simulation results are consistent with the CERES-LA model (RMSE $=$

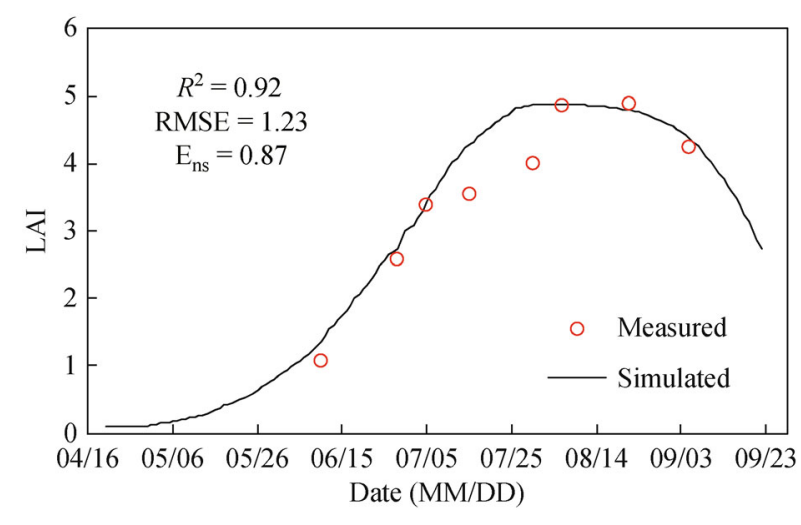

Fig. 7 Comparison between simulated and measured leaf area index

0.86) and are better than the CERES-Maize model (RMSE $=1.25)^{[48]}$. The CropSPAC model over-predicted LAI during the tasseling stage (15 July) and grouting stage (30 July). This may be associated with some unusual environmental conditions (e.g., extreme weather events and plant disease) caused the slow leaf development in that period or it may be caused by the inaccurate measurement method or spatial heterogeneity of crop sampled for data collection.

\subsection{Above-ground biomass and yield}

Crop growth and development requires temperature accumulation which exceeds the basement temperature of crop growth $\left(T_{b}\right)$ to guide meristem formation and development ${ }^{[49]}$. When the meristem is located underground, the rate of maize development is controlled by the soil temperature till the meristem emerges from the soil surface at the elongating stage ${ }^{[50]}$. Mulching increased the topsoil temperature and water content noticeably, which accelerated maize development and improved crop productivity significantly ${ }^{[51]}$. The simulated and measured above-ground biomass is shown in Fig. 8. The simulation

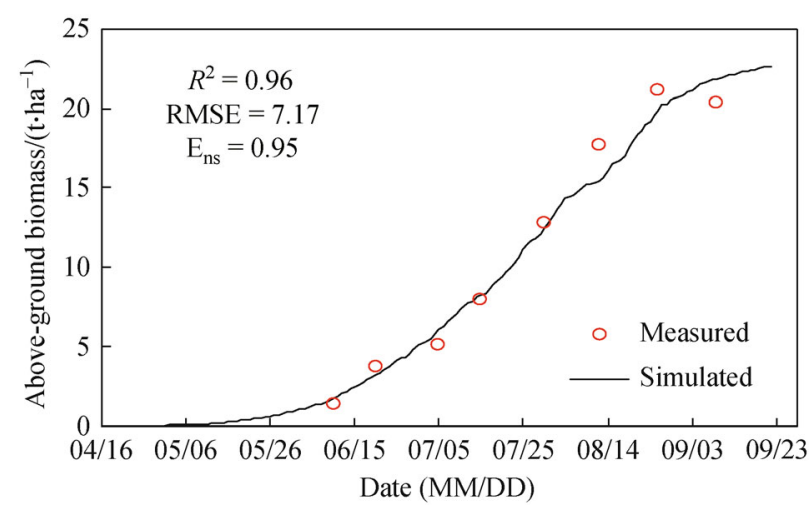

Fig. 8 Comparison between simulated and measured aboveground biomass 
results closely matched the measured values $\left(R^{2}=0.96\right.$, $\mathrm{RMSE}=7.17 \mathrm{t} \cdot \mathrm{ha}^{-1}$ and $\mathrm{E}_{\mathrm{ns}}=0.95$ ), generally showing a continuous nonlinear increasing trend during the growing period. There was a small error between the simulation and the measurement of biomass in the mature stage, possibly caused by the measurement error of the yellow leaves which were not captured in the simulation.

The formation of yield is mainly affected by photosynthesis, transpiration and dry matter accumulation. In the CropSPAC model, the effect of mulching on the yield is mainly reflected in the effect of mulching on evaporation. Table 2 shows the comparison of simulated and measured crop yield. The simulated yield by the crop growth model is $10.8069 \mathrm{t} \cdot \mathrm{ha}^{-1}$ and the measured of yield is $10.322 \mathrm{t} \cdot \mathrm{ha}^{-1}$, the relative error between the simulated value and the measured value is $4.70 \%$. Compared with previous studies this relative error was within a reasonable range ${ }^{[52,53]}$.

Table 2 Comparison between simulated and measured yield $\left(\mathrm{t} \cdot \mathrm{ha}^{-1}\right)$

\begin{tabular}{ccc}
\hline Simulated yield & Measured yield & Relative error $(\delta)$ \\
\hline 10.81 & 10.32 & $4.70 \%$ \\
\hline
\end{tabular}

\section{Simulation under scenarios of climate change and different agronomic measures}

Over recent decades, climate change has shown signs of affecting the ecological environment and agricultural development, thereby threatening global food
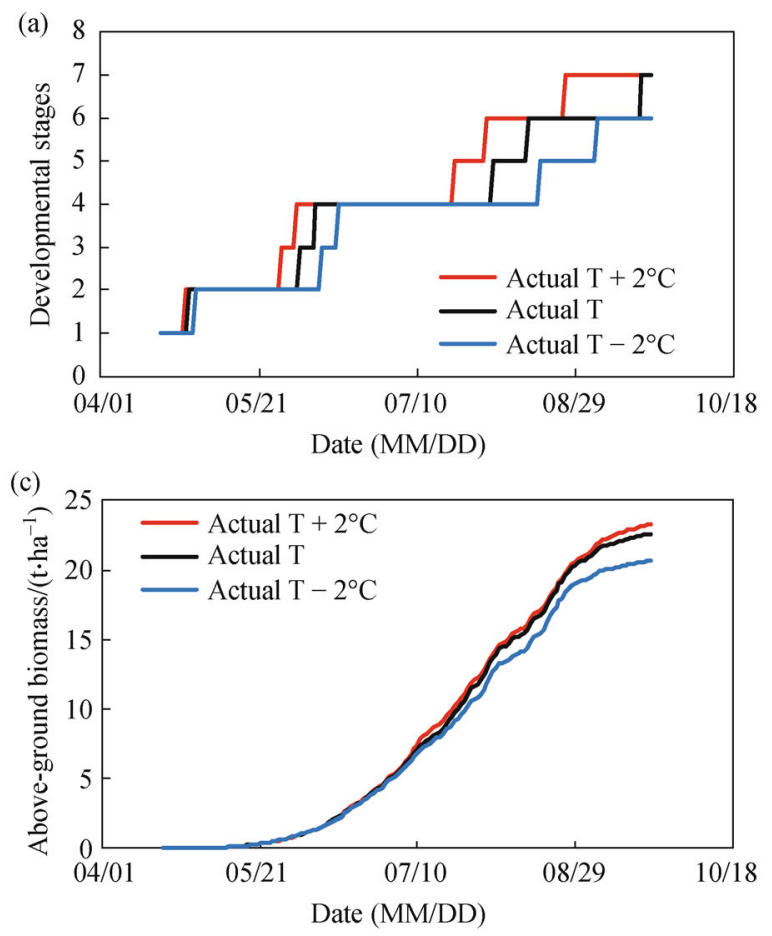

security ${ }^{[54-56]}$. It has been demonstrated that climate change influences leaf development, canopy production and plant growth by altering the physiological characteristics $^{[57,58]}$. To determine how the climate change, specifically the temperature variation, will alter the suitability of crop growth areas, we simulated the responses of soil water/heat and crop growth to the changed temperature condition (plus and minus $2^{\circ} \mathrm{C}$ ) using the modified CropSPAC. Additionally, scenarios were considered with different ratios of film mulching in order to determine how this agronomy measure would influence crop yield.

\subsection{Simulation under changed temperature}

To reflect climate change, the daily averaged temperature, daily maximum temperature and daily minimum temperature were increased and decreased by $2{ }^{\circ} \mathrm{C}$, with the other simulation conditions similar to the experiment of 2012.

\subsubsection{Growing degree-days and leaf area index}

Although there are sound theoretical reasons which support the commonly held belief that a larger stimulation of net $\mathrm{CO}_{2}$ assimilation rates occurs at a higher temperature, this does not necessarily mean that the pattern of biomass and yield responses to temperature is determined by this response ${ }^{[59,60]}$. Figure 9 shows GDD, LAI and leaf biomass change under different temperature simulation conditions, i.e., the original temperature, the
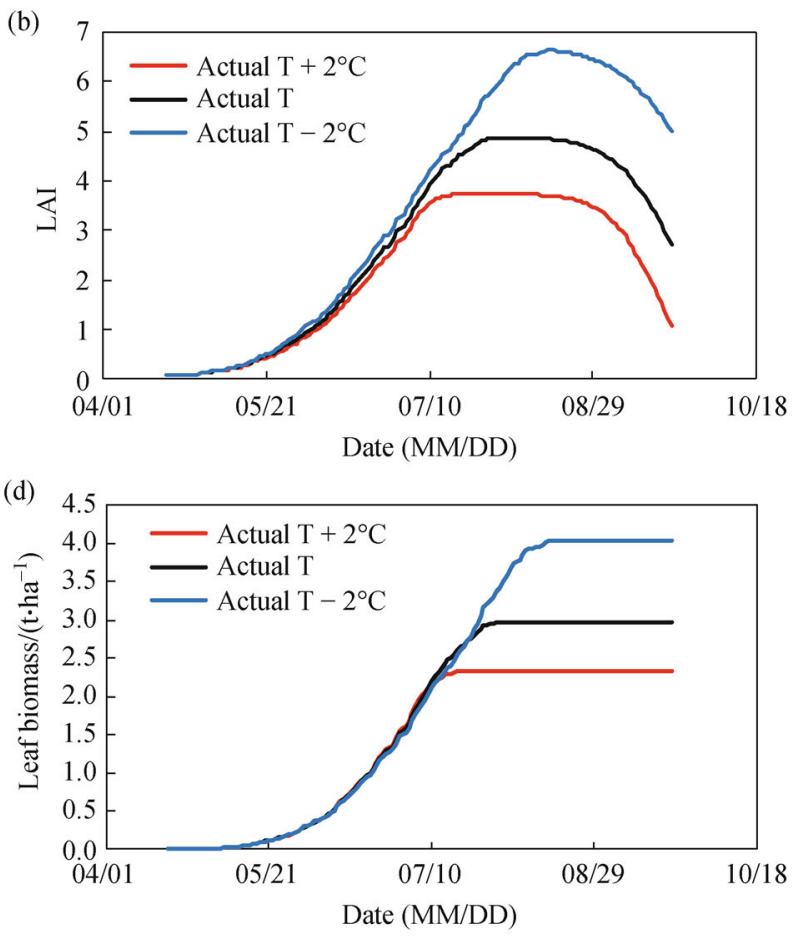

Fig. 9 Simulation of maize developmental stages (a), leaf area index (b), above-ground biomass (c) and leaf biomass (d). T, temperature. 
daily temperature with $2{ }^{\circ} \mathrm{C}$ increase and with $2^{\circ} \mathrm{C}$ decrease. While the GDD was simulated using predicted weather data for a daily temperature increase of $2^{\circ} \mathrm{C}$, the GDD of maize was shortened by nearly $16 \mathrm{~d}$ compared with the original. With the temperature decrease, the maize growth was unable to enter the mature period.

The LAI, leaf biomass and crop yields were negatively correlated with temperature, i.e., LAI, leaf biomass and crop yields decreased while the temperature increased, which is consistent with the field studies made by Brown and Rosenberg ${ }^{[61]}$, who reported that crop yields were inversely related to temperature and a $3{ }^{\circ} \mathrm{C}$ rise in mean annual temperature reduced yield by $2 \%$. Indeed, crop growth may even be inhibited by temperature, and there are lots of studies and experiments aimed at understanding the production gains and losses for particular crops, in different places and various scenarios of climatic change ${ }^{[62-68]}$. Similar conclusions were drawn using

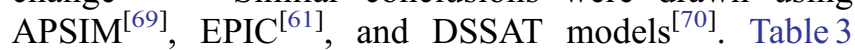
indicates the comparison of temperature change effect on crop yield. The simulated yield by original weather data are $10.8069 \mathrm{t} \cdot \mathrm{ha}^{-1}$, while the yield with daily temperature increase of $2^{\circ} \mathrm{C}$ is $10.5747 \mathrm{t} \cdot \mathrm{ha}^{-1}$ and the yield with daily temperature decrease of $2^{\circ} \mathrm{C}$ is $10.7887 \mathrm{t} \cdot \mathrm{ha}^{-1}$, decreases of $2.15 \%$ and $0.17 \%$, respectively.

\subsubsection{Evaporation and transpiration}

It is generally accepted that rising temperature enhances evaporation and ET, leading to a decline in soil moisture content. However, the temperature effect on LAI is more crucial to evaporation ${ }^{[71]}$. Stomatal control of the exchange of carbon and water vapor between vegetation and the atmosphere is important for global carbon and water cycles. It is generally believed that leaf transpiration is positively correlated with the vapor pressure deficit between leaf stomata and canopy air, but negatively correlated with canopy boundary layer resistance and stomatal resistance. An increment in the leaf stomatal resistance after LAI decline would decrease the total leaf transpiration and presumably decrease water loss ${ }^{[72,73]}$.

Figure 10 shows the response of daily evaporation and transpiration to temperature changes during the maize growth period. It shows similar variation in daily evaporation under different temperature scenarios. In July and August, when the LAI reached its maximum values, leaf transpiration increased significantly. Soil evaporation was mainly influenced by irrigation/precipitation events. The daily evaporation increased in the scenario of temperature increase, while the daily transpiration showed an opposite trend. This is because under temperature increase, LAI decreased (Fig. 8), which led to decreased transpiration.

Table 4 presents the variation of ET and WUE which are limited only by the temperature conditions. The simulation shows that when maize leaf was exposed to lower temperature, ET was higher and WUE lower. The daily ET is $769.8 \mathrm{~mm} \cdot \mathrm{d}^{-1}$ during the simulation period. With the

Table 3 Comparison of the effect of temperature change on yield $\left(\mathrm{t} \cdot \mathrm{ha}^{-1}\right)$

\begin{tabular}{lccc}
\hline Variable & Temperature $+2{ }^{\circ} \mathrm{C}($ Change $)$ & Temperature $-2{ }^{\circ} \mathrm{C}($ Change $)$ & Temperature \\
\hline Yield & $10.57(2.15 \% \downarrow)$ & $10.79(0.17 \% \downarrow)$ & 10.81 \\
\hline
\end{tabular}
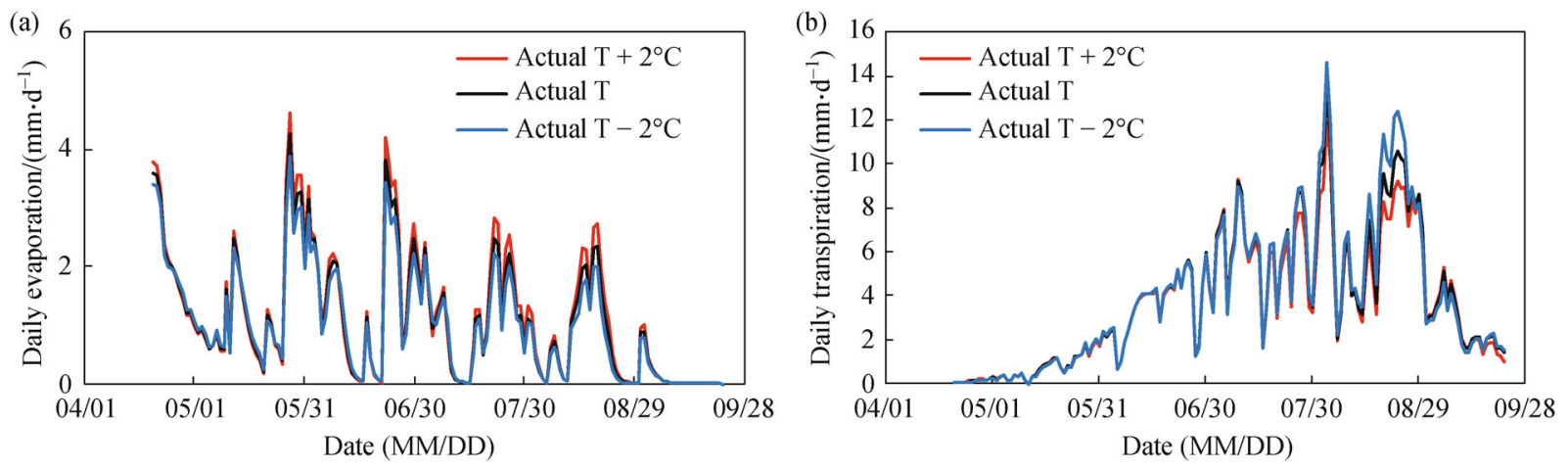

Fig. 10 The simulation of daily evaporation (a) and transpiration (b). T, temperature.

Table 4 Comparison of the effect of temperature change on ET $\left(\mathrm{mm} \cdot \mathrm{d}^{-1}\right)$ and WUE $\left(\mathrm{kg} \cdot \mathrm{ha}^{-1} \cdot \mathrm{mm}^{-1}\right)$

\begin{tabular}{lccc}
\hline Variable & Temperature $+2^{\circ} \mathrm{C}($ Change $)$ & Temperature $-2^{\circ} \mathrm{C}($ Change $)$ & Temperature \\
\hline ET $\left(\mathrm{mm} \cdot \mathrm{d}^{-1}\right)$ & $753.32(2.14 \% \downarrow)$ & $777.14(0.95 \% \uparrow)$ & 769.81 \\
WUE $\left(\mathrm{kg} \cdot \mathrm{ha}^{-1} \cdot \mathrm{mm}^{-1}\right)$ & $14.04(0.01 \% \downarrow)$ & $13.88(0.11 \% \downarrow)$ & 14.04 \\
\hline
\end{tabular}


temperature increase of $2^{\circ} \mathrm{C}$, the daily ET is $753.3 \mathrm{~mm} \cdot \mathrm{d}^{-1}$, a decrease of $2.14 \%$. However, with the temperature decrease of $2^{\circ} \mathrm{C}$, the daily ET is $777.14 \mathrm{~mm} \cdot \mathrm{d}^{-1}$, an increase of $0.95 \%$. Additionally, when the temperature drops, the WUE decreases from 14.04 to 13.88 , a decrease of $0.11 \%$, and the change of temperature increase is not significant.

\subsubsection{Soil water content and soil temperature}

Figure 11 presents the soil water balance in the $0-1 \mathrm{~m}$ soil layer and soil surface temperature change under different temperature conditions. The soil water content is not sensitive to changes in temperature. The average soil water contents for the original temperature and temperature changes $\left(+2^{\circ} \mathrm{C}\right.$ and $\left.-2^{\circ} \mathrm{C}\right)$ were $270.3,273.3$ and $268.2 \mathrm{~mm}$, respectively. In the mature maize period, the difference in soil water content is mainly due to the increase of temperature and LAI decreased, while soil water content increased. However, the change in soil water content with the decrease of temperature showed the opposite trend. The soil surface temperature is sensitive to daily average temperature change. Soil temperature presents a positive correlation with the change of temperature, i.e., when the temperature rises, the surface temperature rises, and vice versa.

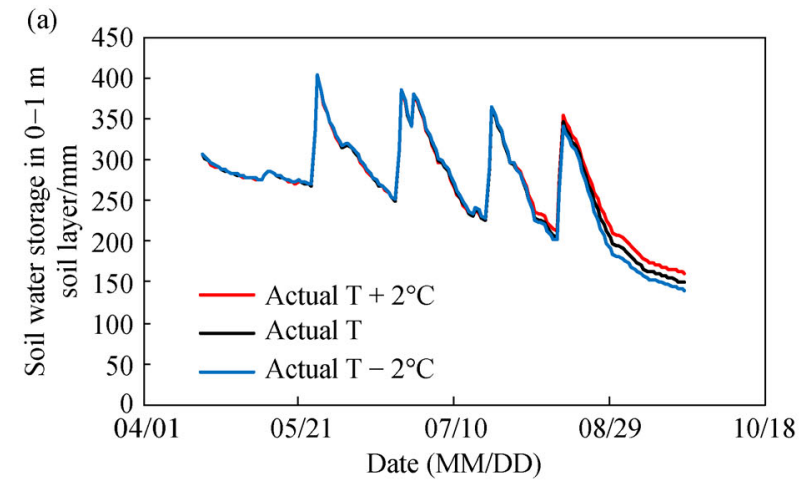

\subsection{Simulation of the different film mulching conditions}

In the modified CropSPAC model, we considered the effect of film mulching on the latent heat consumption and the corresponding influence on energy distribution, soil water and heat transfer and crop water consumption. To quantify the change of soil water and heat condition under different film coverage we changed the ratio of film mulching area $(\alpha)$ to $0,0.2$ and 0.7 . Moreover, we compared the simulation results of the daily evaporation and daily transpiration, sensible heat exchange between soil and canopy air and downward heat flux under different conditions of film coverage.

\subsubsection{Evaporation and transpiration}

Figure 12 shows the simulation results of daily evaporation and transpiration under different ratios of film mulching area $(\alpha)$. Film mulching had a great effect on daily evaporation, especially after irrigation/precipitation. This indicates that film mulching had significantly reduced non-beneficial water consumption. However, the effect of film mulching on crop transpiration was not significant, with a little increase in transpiration with the higher film mulching ratio. This is mainly because the film mulching increased the soil moisture

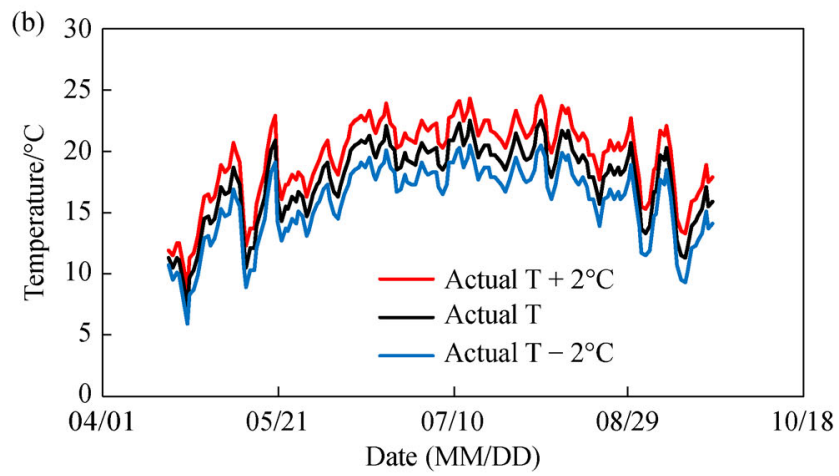

Fig. 11 The simulated and actual soil water content (a) and soil temperature (b). T, temperature.
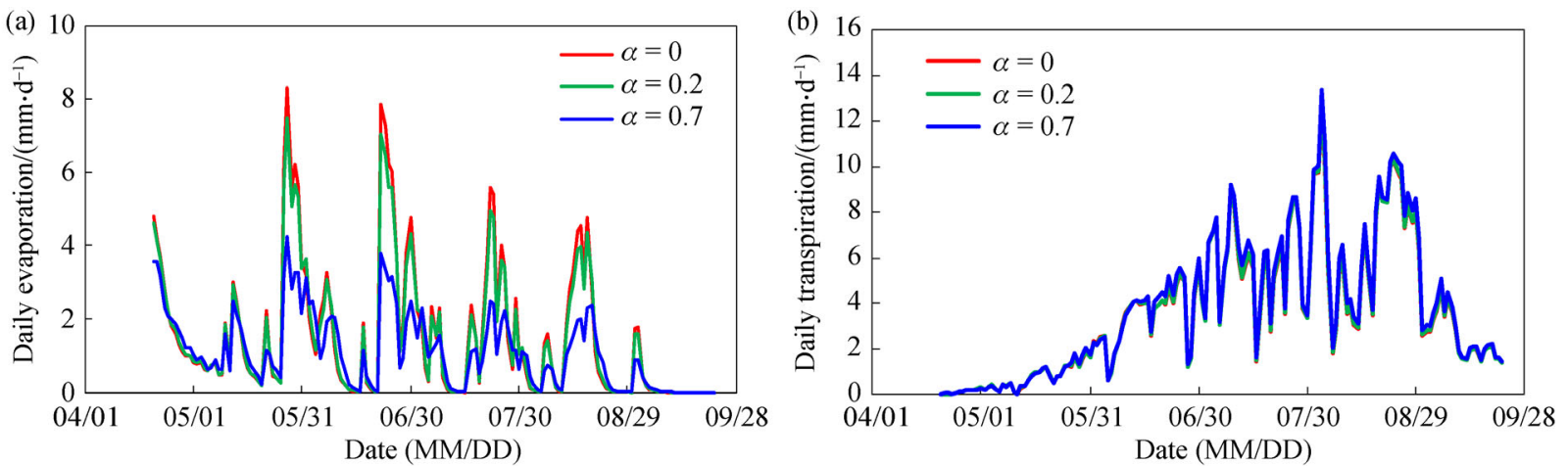

Fig. 12 Simulation of daily evaporation (a) and daily transpiration (b). $\alpha$, ratio of film mulching area. 
and reduced the effect of water stress on the root water uptake.

\subsubsection{Soil water content and soil temperature}

Figure 13 shows the soil water storage in the $0-1 \mathrm{~m}$ soil layer and soil surface temperature change under different ratios of film mulching area. The soil water storage in the 0-1 m soil layer did not show distinct differences under different ratios of film mulching area. This is because the film mulching both reduced the surface soil water consumption (by reducing soil evaporation) and increased the water consumption in the root zone (by increasing the transpiration). Figure 13(b) shows the daily averaged soil surface temperature under different ratios of film mulching area. With the reduction of latent heat consumption on soil surface, film mulching also improved the surface temperature of the soil, especially underlying surface with lower net radiation. The thermal insulation effect is obvious and can weaken the fluctuation of soil surface temperature and maintain the soil surface temperature stability.

\section{Conclusions}

In this study, the existing CropSPAC for winter wheat has been extended to maize. We simulated the growth of maize and considered the effect of the field film mulching. The model was tested in a maize field experiment in the Yingke irrigation area in North China. Results show good agreement between the measured and simulated data about LAI, above-ground biomass and soil water content. Fitting of predicted and actual results was good and the dynamics of soil water heat transfer interactions are reasonably described by the model throughout the whole crop growth season. We believe that such a simulation tool may be useful in a general context for input reduction in agricultural irrigation water management and water conservation.

Moreover, we also investigated different scenarios for predicting the response of crop growth and soil water/heat conditions to climate change and different ratios of film mulching, namely the daily temperature change $\left(+2^{\circ} \mathrm{C}\right.$ and $-2^{\circ} \mathrm{C}$ ) and ratios of film mulching area $(\alpha)$ of $0,0.2$ and 0.7 , both over the whole crop growth period. The simulation results indicate that temperature change has a negative effect on the LAI, leaf biomass and yield by limiting the rate of photosynthesis. Further, the GDD of maize was shortened by nearly $16 \mathrm{~d}$ under the conditions of daily temperature increase $2^{\circ} \mathrm{C}$, but the growth of maize was not able to enter the mature period and resulted in lower production. Furthermore, the simulated results indicated that the soil evaporation decreased as the ratios of film mulching area increased, but this had little impact on leaf transpiration. Soil water storage in the $0-1 \mathrm{~m}$ soil layer did not show distinct differences under different ratios of film mulching area.

Despite our efforts on model validation, there were some distinct discrepancies between the model simulation and measured values for soil water content and yield. Several items should be improved in the simulation of mulching condition. For example, in this model, we arbitrarily assumed the soil evaporation decreased linearly with the increase in ratios of film mulching area and we did not consider the heat insulating effect of the still air layer between the film mulching and the soil surface. Also, when the film has a higher transmittance to solar thermal radiation, the effective radiation between the film and the ground will increase over that of the bare ground. When there is a condensation layer on the surface of the film, the capacity of long-wave radiation will be increased and the effective radiation of the film surface will be less than that of the bare ground. Therefore, the absorption of long-wave radiation by the condensation layer on the surface of the plastic film will have an effect on soil temperature increment, which will require more data to explain. In future research, experiments in laboratory or in field should be designed to test how the distance between plastic film and soil and the film mulching ration influence heat conductance and water vapor diffusion. The experimental results obtained should be embedded into the model to improve its accuracy.
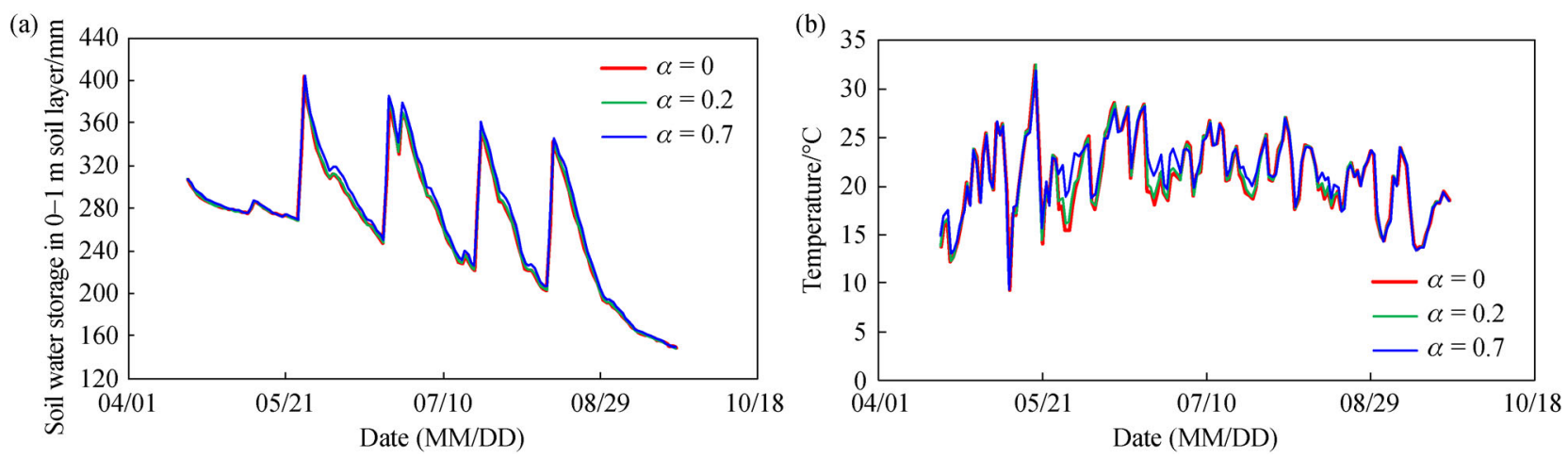

Fig. 13 The simulation of soil water content (a) and soil temperature (b). $\alpha$, ratio of film mulching area. 
Acknowledgements This work was supported by the National Natural Science Foundation of China (51679234 and 51790535) and the National Key Research and Development Program of China (2016YFC040106-3)

Compliance with ethics guidelines Meng Duan, Jin Xie, and Xiaomin Mao declare that they have no conflicts of interest or financial conflicts to disclose.

This article does not contain any studies with human or animal subjects performed by any of the authors.

\section{References}

1. Philip J R. Plant water relations: some physical aspects. Annual Review of Plant Physiology, 1966, 17(1): 245-268

2. Gardner W R. Dynamic aspects of water availability to plants. Soil Science, 1960, 89(2): 63-73

3. Cowan I R. Transport of water in the soil-plant-atmosphere system. Journal of Applied Ecology, 1965, 2(1): 221-239

4. Molz F J, Remson I. Extracting tern model of soil moisture use of transpiring plants. Water Resources Research, 1970, 6(5): 13461356

5. Nimah M N, Hanks R J. Model for estimating soil water, plant, and atmospheric interrelations: I. description and sensitivity. Soil Science Society of America Journal, 1973, 37(4): 522-527

6. Feddes R A, Kowalik P J, Zaradny H. Simulation of field water use and crop yield. Soil Science, 1982, 129(3): 193

7. Hoogland J C, Feddes R A, Belmans C. Root water uptake model depending on soil water pressure head and maximum extraction rate. Acta Horticulturae, 1981, 36(119): 123-136

8. Molz F J. Models of water transport in the soil-plant system: a review. Water Resources Research, 1981, 17(5): 1245-1260

9. Prasad R. A linear root water uptake model. Journal of Hydrology, 1988, 99(3-4): 297-306

10. Thom A S. Momentum, mass, and heat exchange of plant communities. Vegetation \& the Atmosphere, 1975, 2(1): 57-109

11. Bailey W G, Davies J A. The effect of uncertainty in aerodynamic resistance on evaporation estimates from the combination model. Boundary-Layer Meteorology, 1981, 20(2): 187-199

12. de Vries F W T P. A model for simulating transpiration of leaves with special attention to stomatal functioning. Journal of Applied Ecology, 1972, 9(1): 57-78

13. Jarvis $\mathrm{P}$ G. The interpretation of the variations in leaf water potential and stomatal conductance found in canopies in the field. Philosophical Transactions of the Royal Society of London. Series B: Biological Sciences, 1976, 273(927): 593-610

14. Noilhan J, Planton S. A simple parameterization of land surface processes for meteorological models. Monthly Weather Review, 1989, 117: 536-549

15. Mao X M, Shang S H, Lei Z D, Yang S X. Study on evapotranspiration of winter wheat using SPAC model. Journal of Hydraulic Engineering, 2001, 32(8): 7-12 (in Chinese)

16. van de Griend A A, van Boxel J H. Water and surface energy balance model with a multilayer canopy representation for remote sensing purposes. Water Resources Research, 1989, 25(5): 949-971

17. Whisler F D, Acock B, Baker D N, Fye R E, Hodges H F, Lambert J R, Lemmon H E, Mckinion J M, Reddy V R. Crop simulation models in agronomic systems. Advances in Agronomy, 1986, 40(1): $141-208$

18. Kropff M J, Spitters C J T. A simple model of crop loss by weed competition from early observations on relative leaf area of the weeds. Weed Research, 1991, 31(2): 97-105

19. Walker G K. CERES-maize (book review). Bulletin of the American Meteorological Society, 1987, 68(3): 513-514

20. Brown D M. CERES-Maize: a simulation model of maize growth and development. Agricultural and Forest Meteorology, 1987, 41 (3-4): 339-339

21. Peake A S, Robertson M J, Bidstrup R J. Optimising maize plant population and irrigation strategies on the Darling Downs using the APSIM crop simulation model. Australian Journal of Experimental Agriculture, 2008, 48(3): 313-325

22. Yang H S, Dobermann A, Lindquist J L, Walters D T, Arkebauer T J, Cassman K G. Hybrid-maize - a maize simulation model that combines two crop modeling approaches. Field Crops Research, 2004, 87(2-3): 131-154

23. Diepen C A, Wolf J, Keulen H, Rappoldt C. WOFOST: a simulation model of crop production. Soil Use and Management, 2010, 5(1): $16-24$

24. Hsiao T C, Heng L, Steduto P, Rojas-Lara B, Raes Dirk, Fereres E. AquaCrop - the FAO crop model to simulate yield response to water: III. parameterization and testing for maize. Agronomy Journal, 2009, 101(3): 448-459

25. Monteith J L. Evaporation and environment. Symposia of the Society for Experimental, 1965, 19(19): 205-234

26. Cowan I R. Transport of water in the soil-plant-atmosphere system. Journal of Applied Ecology, 1965, 2(1): 221-239

27. Yang W C, Mao X M, Yang J, Ji M M, Adeloye A J. A coupled model for simulating water and heat transfer in soil-plant-atmosphere continuum with crop growth. Water, 2019, 11(1): 47

28. Mcmaster G S, Wilhelm W W. Growing degree-days: one equation, two interpretations. Agricultural and Forest Meteorology, 1997, 87 (4): 291-300

29. Allan J C, Kiniry J R, Dyke P T. CERES-Maize: a Simulation Model of Maize Growth and Development. US: Texas A\&M University Press, 1986(3): 49-111

30. Thornley J H M. Dynamic model of leaf photosynthesis with acclimation to light and nitrogen. Annals of Botany, 1998, 81(3): $421-430$

31. Collatz G J, Ribascarbo M, Berry J A. Coupled photosynthesisstomatal conductance model for leaves of $\mathrm{C}_{4}$ plants. Australian Journal of Plant Biology, 1992, 19(5): 519-538

32. Amthor J S. Respiration and crop productivity. Quarterly Review of Biology, 1989, 10(3): 271-273

33. Iersel M W V, Seymour L. Growth respiration, maintenance respiration, and carbon fixation of vinca: a time series analysis. Journal of the American Society for Horticultural Science American Society for Horticultural Science, 2000, 125(6): 702-706

34. Abrecht D G, Carberry P S. The influence of water deficit prior to tassel initiation on maize growth, development and yield. Field Crops Research, 1993, 31(1-2): 55-69

35. Hawkins R C, Cooper P J M. Growth, development and grain yield of maize. Experimental Agriculture, 1981, 17(2): 203-207

36. Camillo P J, Gurney R J. A resistance parameter for bare soil 
evaporation models. Soil Science, 1986, 141(2): 95-105

37. Choudhury B J, Monteith J L. A four-layer model for the heat budget of homogeneous land surfaces. Quarterly Journal of the Royal Meteorological Society, 1988, 114(480): 373-398

38. Zribi W, Aragüés R, Medina E, Faci J M. Efficiency of inorganic and organic mulching materials for soil evaporation control. Soil \& Tillage Research, 2015, 148(3): 40-45

39. Stewart J B. Measurement and prediction of evaporation from forested and agricultural catchments. Agricultural Water Management, 1984, 8(1-3): 1-28

40. Bristow K L, Horton R. Modeling the impact of partial surface mulch on soil heat and water flow. Theoretical and Applied Climatology, 1996, 54(1-2): 85-98

41. Wu Y, Huang F, Zhang C, Jia Z K. Effects of different mulching patterns on soil moisture, temperature, and maize yield in a semiarid region of the Loess Plateau, China. Arid Soil Research and Rehabilitation, 2016, 30(4): 490-504

42. Karandish F, Shahnazari A. Soil temperature and maize nitrogen uptake improvement under partial root-zone drying irrigation. Pedosphere, 2016, 26(6): 872-886

43. Jabran K, Ullah E, Akbar N. Mulching improves crop growth, grain length, head rice and milling recovery of basmati rice grown in water-saving production systems. International Journal of Agriculture and Biology, 2015, 17(5): 920-928

44. Flerchinger G N, Hanson C L, Wight J R. Modeling evapotranspiration and surface energy budgets across a watershed. Water Resources Research, 1996, 32(8): 2539-2548

45. Gusev Y M, Nasonova O N. Modelling annual dynamics of soil water storage for agro- and natural ecosystems of the steppe and forest-steppe zones on a local scale. Agricultural and Forest Meteorology, 1997, 85(3-4): 171-191

46. Scott R, Entekhabi D, Koster R, Suarez M. Timescales of land surface evapotranspiration response. Journal of Climate, 1997, 10 (4): 559-566

47. Daamen C C, Simmonds L P. Measurement of evaporation from bare soil and its estimation using surface resistance. Water Resources Research, 1996, 32(5): 1393-1402

48. Lizaso J I, Batchelor W D, Westgate M E. A leaf area model to simulate cultivar-specific expansion and senescence of maize leaves. Field Crops Research, 2003, 80(1): 1-17

49. Warrington I J, Kanemasu E T. Corn growth response to temperature and photoperiod II. Leaf-initiation and leaf-appearance rates. Agronomy Journal, 1983, 75(5): 755-761

50. Bano S, Aslam M, Saleem M, Basra S M. Evaluation of maize accessions under low temperature stress at early growth stages. Journal of Animal \& Plant Sciences, 2015, 25(2): 392-400

51. Igbadun H E, Ramalan A A, Oiganji E. Effects of regulated deficit irrigation and mulch on yield, water use and crop water productivity of onion in Samaru, Nigeria. Agricultural Water Management, 2012, 109(9): 162-169

52. Ren J, Chen Z, Tang H, Zhou Q B. Regional crop yield simulation based on crop growth model and remote sensing data. Transactions of the Chinese Society of Agricultural Engineering, 2011, 27(8): 257-264 (in Chinese)

53. Mohammadi M, Ghahraman B, Davary K, Ansari1 H, Shahidi A. Validation of AquaCrop model for simulation of winter wheat yield and water use efficiency under simultaneous salinity and water stress. Majallah-i āb va Khāk, 2016, 29(1): 67-84

54. Klare M T. Global warming battlefields: how climate change threatens security. Current History, 2007, 106(703): 355-361

55. Pachauri K, Meyer A. Climate change 2014 synthesis report. Environmental Policy Collection, 2014, 27(2): 408

56. Peng F, Sun G D. Variation of leaf area index in China from 1982 to 1999 and its relationship with climate change. Climatic \& Environmental Research, 2017, 22(2): 162-176 (in Chinese)

57. Ying J, Lee E A, Tollenaar M. Response of maize leaf photosynthesis to low temperature during the grain-filling period. Field Crops Research, 2000, 68(2): 87-96

58. Zheng Y P, Li R Q, Guo L L, Hao L H, Zhou H R, Li F, Peng Z P, Cheng $\mathrm{D} \mathrm{J}, \mathrm{Xu}$ M. Temperature responses of photosynthesis and respiration of maize (Zea mays) plants to experimental warming. Russian Journal of Plant Physiology: a Comprehensive Russian Journal on Modern Phytophysiology, 2018, 65(4): 524-531

59. Berry J, Bjorkman O. Photosynthetic response and adaptation to temperature in higher plants. Annual Review of Plant Physiology, 1980, 31(1): 491-543

60. Tranquillini W, Havranek W M, Ecker P. Effects of atmospheric humidity and acclimation temperature on the temperature response of photosynthesis in young Larix decidua Mill. Tree Physiology, 1986, 1(1): 37-45

61. Brown R A, Rosenberg N J. Sensitivity of crop yield and water use to change in a range of climatic factors and $\mathrm{CO}_{2}$ concentrations: a simulation study applying EPIC to the central USA. Agricultural and Forest Meteorology, 1997, 83(3-4): 171-203

62. Rosenberg $\mathrm{N} \mathrm{J}$. The increasing $\mathrm{CO}_{2}$ concentration in the atmosphere and its implication on agricultural productivity II. Effects through $\mathrm{CO}_{2}$-induced climatic change. Climatic Change, 1982, 4(3): 239254

63. Mcleod A R, Long S P. Free-air carbon dioxide enrichment (FACE) in global change research: a review. Advances in Ecological Research, 1999, 28(8): 1-56

64. Reddy S J. Sensitivity of some potential evapotranspiration estimation methods to climate change. Agricultural and Forest Meteorology, 1995, 77(1-2): 121-125

65. Helms S, Mendelsohn R, Neumann J. The impact of climate change on agriculture. Climatic Change, 1996, 33(1): 1-6

66. Chavas D RCésar Izaurralde, R., Thomson A M, Gao X J. Longterm climate change impacts on agricultural productivity in eastern China. Agricultural and Forest Meteorology, 2009, 149(6-7): 11181128

67. Lobell D B, Burke M B. On the use of statistical models to predict crop yield responses to climate change. Agricultural and Forest Meteorology, 2010, 150(11): 1443-1452

68. Iizumi T, Ramankutty N. How do weather and climate influence cropping area and intensity? Global Food Security, 2015, 4: 46-50

69. Asseng S, Jamieson P D, Kimball B, Pinter P, Sayre K, Bowden J W, Howden S M. Simulated wheat growth affected by rising temperature, increased water deficit and elevated atmospheric $\mathrm{CO}_{2}$. Field Crops Research, 2004, 85(2): 85-102

70. Boote K J, Prasad V, Allen L H, Singh P. Modeling sensitivity of grain yield to elevated temperature in the DSSAT crop models for peanut, soybean, dry bean, chickpea, sorghum, and millet. European 
Journal of Agronomy, 2017, 9(2): 99-109

71. Aniah P, Kaunzanudem M K, Abindaw B A, Millar D. Characterizing and explaining smallholder households' views and understanding of climate change in the Bongo district of Ghana. Earth Sciences, 2016, 5(2): 26-38
72. Chahine M T. The hydrological cycle and its influence on climate. Nature, 1992, 359(6394): 373-380

73. Jackson R B, Sperry J S, Dawson T E. Root water uptake and transport: using physiological processes in global predictions. Trends in Plant Science, 2000, 5(11): 482-488 